\title{
CHARACTERIZATION OF THE INTESTINAL TRANSPORT PARAMETERS FOR SMALL PEPTIDE DRUGS ${ }^{\star}$
}

\author{
Doron I. Friedman and Gordon L. Amidon* \\ College of Pharmacy, The University of Michigan, Ann Arbor, MI 48109-1065 (U.S.A.)
}

(Received August 30, 1989; accepted in revised form January 5, 1990)

Keywords: ACE inhibitors; $\beta$-lactams; oral bioavailability of peptide drugs; carrier-mediated transport; absorption kinetics

Several laboratories have recently shown that many peptides and peptide-similar drugs are well absorbed in the mammalian intestine via the peptide transport system for nutrient small peptide (dipeptides and tripeptides) absorption. This facilitated non-passive transport in the intestine is saturable and concentration dependent, and further characterized by the mutual inhibition of transport among the compounds. Peptide and peptide derivative drugs are often zwitterionic compounds, generally ionized at the intestinal $\mathrm{pH}$ and therefore are expected to undergo only limited passive absorption. Nonpassive and passive transport are independent and may occur simultaneously. Peptide drugs that have been shown to be transported by the peptide carrier systems are various $\beta$-lactams, the angiotensin converting enzyme (ACE) inhibitors captopril, enalapril, lisinopril and $S Q 29,852, T R H$ and its analogues, and alafosfaline and some of its analogues. The carrier characterization is based upon transport parameters, $\mathrm{K}_{m}, \mathrm{~J}_{\max }$ (or $\mathrm{V}_{\max }$ ) and $\mathrm{P}_{c}$ (Michaelis-Menten constant, maximal flux and the carrier permeability constant respectively) determined over the last years for several dipeptides, $\beta$-lactam antibiotics and ACE inhibitors.

\section{INTRODUCTION}

Proteins and peptides are hydrolyzed by proteolytic enzymes while traversing the G.I. system to finally reach the intestinal absorptive membrane either as readily absorbable amino acids or as short peptides [1]. Uptake of the short peptides into the intestinal microvillus cells is accomplished by the peptide carrier transport system and is restricted to dipeptides

\footnotetext{
*Paper presented at the Second International Symposium on Disposition and Delivery of Peptide Drugs (F.I.P. Satellite Symposium) held at Leiden, The Netherlands, 1-3 September 1989.

*To whom correspondence about this paper should be addressed.
}

and tripeptides. Larger peptides are hydrolyzed by the brush border enzymes before being absorbed as tripeptides, dipeptides or amino acids. The peptide carrier is distinct from the amino acid transport carriers. The small peptide carrier transports dipeptides and tripeptides of different amino composition and is versatile towards many structure modifications as will be shown in this paper. Nevertheless, this peptide carrier has not yet been described in a way that enables structure-uptake relationship prediction.

Many peptide drugs which are derivatives of dipeptides and tripeptides are absorbed in a facilitated manner via the peptide carrier-mediated transport system [2-12]. Unlike large 
peptide and protein drugs, which are highly susceptible to proteolytic enzymes and are currently administered parenterally, small peptide or peptide-like drugs are more suitable for oral administration. Non-passive transport can provide an efficient route for absorption for these compounds which are generally charged or zwitterionic at the physiological $\mathrm{pH}$ and may not readily penetrate the lipophilic intestinal membrane.

Transport via the peptide carrier-mediated system is a saturable and concentration dependent phenomenon which is characterized by the Michaelis-Menten constants $K_{\mathrm{m}}$ and $J_{\max }$ (or $\left.V_{\max }\right)$. Uptake inhibition by other compounds transported by the peptide carrier is typical of this type of carrier-mediated transport. Although apparent competitive inhibition seems to occur, the inhibition mechanism for peptide drugs has not yet been extensively studied.

Passive transport of peptide derivative drugs may occur simultaneously with a non-passive transport and it is proportional to the relative hydrophobic character of the compound. While passive transport may take place along the entire intestine, nonpassive transport via the peptide carrier may exhibit a site-specific absorption profile due to the localization of the carrier to the small intestine.

The in situ jejunal perfusion or ex vivo jejunal rings and everted intestine have been frequently employed to characterize carrier-mediated transport. Varying drug concentrations are used to detect Michaelis-Menten uptake behavior and to define the transport parameters, $K_{\mathrm{m}}, J_{\max }$ and $P_{\mathrm{c}}\left(J_{\max } / K_{\mathrm{m}}\right)$. Transport inhibitors are studied in order to validate nonpassive transport and explore its mechanism. The penicillins which are D (Ala)-D (Ala) analogues were the first peptide drugs identified to be transported non-passively in the intestine by the peptide carrier-mediated transport system. Subsequently, the absorption mechanism of other $\beta$-lactams was recognized to involve a nonpassive transport [2-7]. Other groups of bioactive compounds absorbed in a non-passive manner are thyrotrophin-releasing hormone (TRH) and its analogues which are tripeptide and tripeptide derivatives [8] and alafosfalines which comprise a unique group of antibiotics undergoing hydrolysis concurrently with absorption by the peptide carrier transport system [9]. More recently, several angiotensin converting enzyme (ACE) inhibitors which are dipeptide and tripeptide derivatives were shown to be transported by the intestinal peptide carrier-mediated transport system and their transport profile and Michaelis-Menten parameters were defined [10-12].

In this paper the carrier transport parameters $K_{\mathrm{m}}, J_{\max }$ and $J_{\max } / K_{\mathrm{m}}\left(P_{\mathrm{c}}\right)$ for the $\beta$-lactam antibiotics and ACE inhibitors are reviewed and compared in order to initiate a structure-absorption characterization of the intestinal small peptide carrier-mediated transport system.

\section{TRANSPORT PARAMETERS FOR SMALL PEPTIDE DRUGS}

Detailed transport parameters are available for several hydrolysis stable dipeptides, $\beta$-lactam antibiotics and ACE inhibitors. The transport parameters are the permeability parameters $P_{c}$ and $P_{m}$ for non-passive (carrier) and for passive diffusion transport pathways, respectively and the maximal transport rate $V_{\max }$ (or $J_{\max }$ ) and the Michaelis-Menten constant, $K_{\mathrm{m}}$, for non-passive transport. The data presented in Table 1 are transport parameters derived from in situ single-pass rat perfusion applying the boundary layer solution for estimation of the aqueous permeability [13].

The interaction between the peptide and the carrier is a primary factor in the nonpassive or facilitated transport phenomenon. Unlike the more specific amino acid carriers identified, the peptide carrier transports a variety of di- and tripeptides composed of different amino acids 


\section{TABLE 1}

Summary of permeability data for some dipeptides and peptide drugs $\beta$-lactams and ACE inhibitors (*-dimensionless parameter, $K_{\mathrm{m}}$-Michaelis-Menten constant in $\mathrm{m} M, J_{\max }^{*}$-maximal transport rate, $P_{\mathrm{c}}^{*}=J_{\max }^{*} / \mathrm{K}_{\mathrm{m}}$-the carrier transport parameter, $P_{\mathrm{m}}^{*}$-dimensionless passive parameter)

\begin{tabular}{lcclllr}
\hline Compound & $K_{\mathrm{m}}$ & $J_{\max }^{*}$ & $P_{\mathbf{c}}^{*}$ & $P_{\mathrm{m}}^{*}$ & Inhibitor & Ref. \\
\hline Peptides & & & & & & 3 \\
Carnosine & 12.9 & 6.62 & 0.51 & - & & 3 \\
Phe-Gly & 1.29 & 6.87 & 5.33 & - & & 21 \\
$\beta$-Lactams & & & & & & 6 \\
Amoxicillin & 0.058 & 0.044 & 0.558 & 0.76 & & 6 \\
Cefaclor & 16.1 & 21.3 & 1.32 & 0.00 & & 6 \\
Cefadroxil & 5.9 & 8.4 & 1.43 & 0.00 & Cyclacillin, Gly-Gly & 6 \\
Cefatrizine & 0.58 & 0.73 & 1.25 & 0.20 & & Cyclacillin, Gly-Gly \\
Cephalexin & 7.2 & 9.1 & 1.30 & 0.00 & Cephalexin,Gly-Leu & 21 \\
Cephradine & 1.48 & 1.57 & 1.06 & 0.30 & Carnosine,Gly-Pro & \\
Cefixime & 0.031 & 0.016 & 0.184 & 0.52 & & 10 \\
ACE inhibitors & & & & & Gly-Gly, Cephradine & 1 \\
Captopril & 5.9 & 12.3 & 2.08 & 1.00 & Tyr-Gly, Cephradine & 11 \\
Enalapril & 0.07 & 0.13 & 1.9 & 0.35 & Tyr-Gly, Cephradine & 12 \\
Lisinopril & 0.082 & 0.032 & 0.39 & 0.00 & Tyr-Gly,Cephradine & 12 \\
SQ 29,852 & 0.080 & 0.160 & 2.00 & 0.25 & & \\
\hline
\end{tabular}

and peptide-like drugs which bear various substitution groups and which are not necessarily natural peptides by their chemical structure.

Although some evidence for the existence of multiple peptide carriers has been recently published [14], it has not been confirmed and so remains to be resolved. The parameters presented in Table 1 for peptide transport demonstrate different "affinities" of the peptide for the carrier as well as variability with respect to stability against enzymatic hydrolysis. For example, carnosine ( $\beta$-Ala-His) is very stable against enzymatic hydrolysis and therefore was extensively studied [3].

It is difficult to compare non-passive transport parameters measured by different laboratories due to differing experimental approaches and methods for the calculation of $J_{\max }$. Since $J_{\max }$ and $J_{\max } / K_{\mathrm{m}}$ may be calculated for a specific amount of dry or wet tissue weight, protein or intestinal length or surface area, a simple transformation and matching of the data is impossible. We will focus on results from our laboratory for consistency $[5,6,10-12]$.

\section{MACROSCOPIC CORRELATION}

The transport parameters for several acid stable $\beta$-lactam antibiotics are presented in $\mathrm{Ta}$ ble 1 . The carrier permeability parameter, $P_{\mathrm{c}}^{*}$ or $J_{\max }^{*} / K_{\mathrm{m}}$, is relatively constant for these $\beta$-lactam antibiotics while $J_{\max }^{*}$ and $K_{\mathrm{m}}$ vary more significantly. The $K_{\mathrm{m}}$ and $J_{\max }^{*}$, as summarized in Table 1 , for the different $\beta$-lactams are correlated in Fig. 1 with the maximal plasma levels, $C_{\text {max }}$, in humans after a $500 \mathrm{mg}$ oral dose. The $C_{\max }$ values in Fig. 1 are the mean values of the reported maximal plasma levels [15]. A significant correlation between $K_{\mathrm{m}}$ and $C_{\max }$ after oral administration of the different $\beta$-lactams is observed. The maximal plasma concentration, $C_{\max }$, after a $500 \mathrm{mg}$ oral dose for several $\beta$-lactams increases as $K_{\mathrm{m}}$ increases. Since $J^{*}{ }_{\text {max }}$ also increases proportionally, $J^{*}{ }_{\max } / K_{\mathrm{m}}$ will not change significantly between the various $\beta$-lactams studied and the permeability constant of the carrier may therefore be assumed relatively constant. From this correlation it can be concluded that the maximal flux or the carrier ca- 


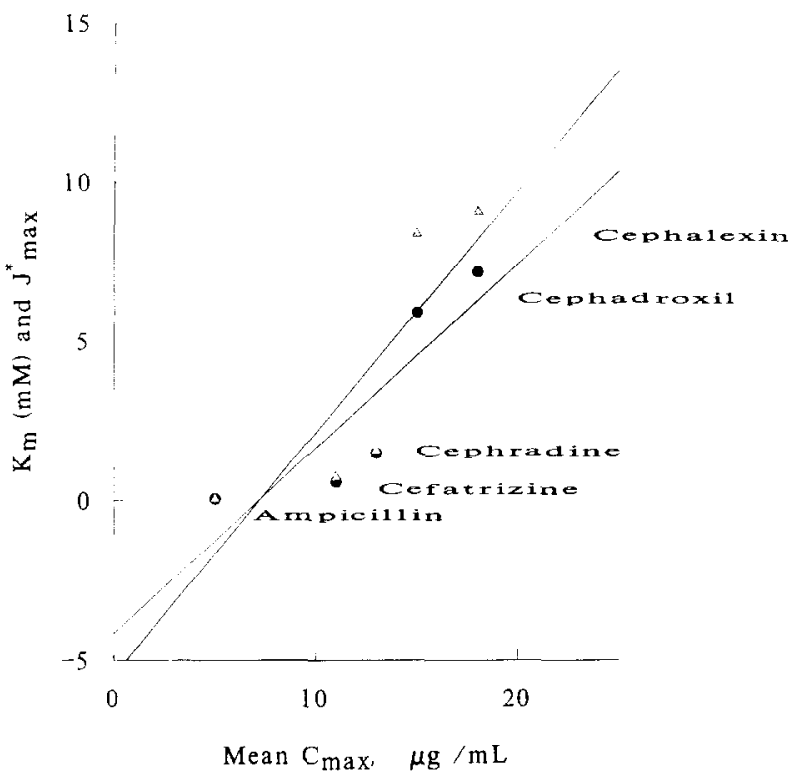

Fig. 1. (๑) Michaelis-Menten constant $\left(K_{\mathrm{m}}, \mathrm{m} M\right)$ and $(\triangle)$ dimensionless maximal flux $\left(J^{*}{ }_{\max }\right)$ as derived from in situ jejunal rat perfusion versus mean reported maximal plasma concentration $\left(C_{\max }\right)$ after $500 \mathrm{mg}$ oral administration of $\beta$-lactams in humans.

pacity for the specific $\beta$-lactam has the highest impact on the absorption process and subsequent human plasma levels. Higher capacity low-affinity $\beta$-lactams are better absorbed. This correlation is further supported by the fact that higher doses do not always produce a proportional area under curve (AUC) for the $\beta$-lactams with low $K_{\mathrm{m}}$, while only a very slight trend towards non-linear pharmacokinetics is reported for $\beta$-lactams with $K_{\mathrm{m}}$ above $4.0 \mathrm{mM}$. As the $K_{\mathrm{m}}$ and $J_{\max }^{*}$ increase, it is less likely for the drug to saturate the carrier. Beta-lactams with low $K_{\mathrm{m}}$ and dose dependent bioavailability include ampicillin and cyclacillin and those with relatively higher $K_{\mathrm{m}}$ include cephradine, cephalexin and cephadroxil. The latter group, with relatively high $J_{\max }^{*}$ and $K_{\mathrm{m}}$, are completely absorbed in humans while amoxicillin and cyclacillin are not.
For the ACE inhibitors, a linear relation is shown in Fig. 2 between $J_{\max }^{*}$ (as measured in rat jejunum) and fraction of dose absorbed in humans ( $\%$ oral bioavailability). It can be concluded that, for the ACE inhibitors, the $J_{\max }^{*}$ or the capacity of the peptide carrier in the intestine is the rate limiting factor for bioavailability. The carrier permeability, $J_{\max }^{*} / K_{\mathrm{m}}$, is $2.0 \pm 0.1$ for captopril, enalapril and SQ 29,852 and is lower, 0.39 , for lisinopril. The low capacity and carrier permeability of lisinopril results in lower non-passive permeability and poor bioavailability. A more general relationship between fraction of dose absorbed in human and rat jejunal permeability parameters has been published elsewhere [16].

Apparently two distinct drug carrier affinity profiles are observed: the $\beta$-lactams transport parameters show consistently high capacity and low affinity to the carrier while the ACE inhibitors show low capacity and high affinity. The kinetic mechanism that accounts for this difference is yet unknown.

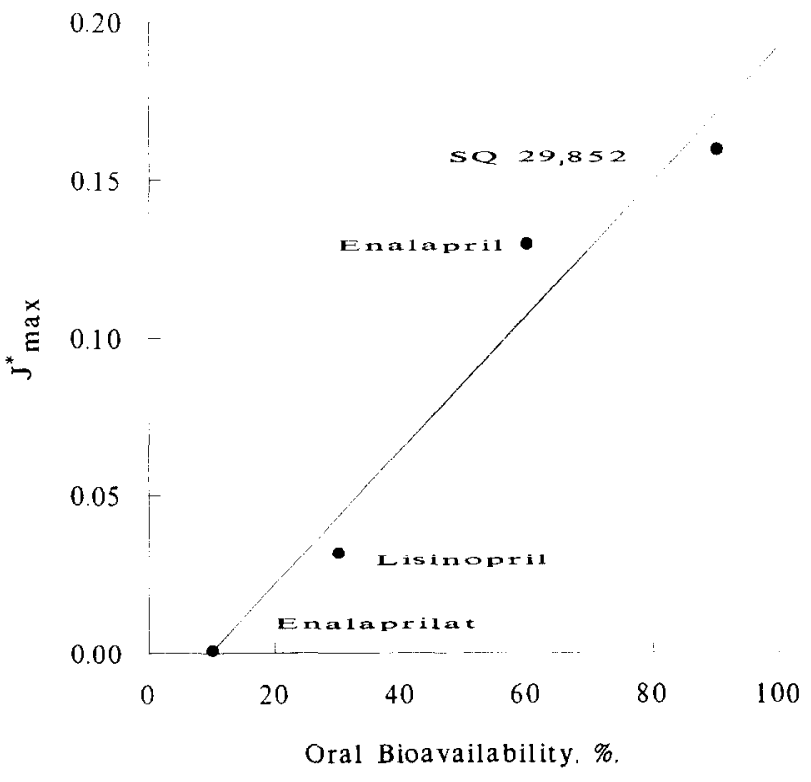

Fig. 2. The dimensionless maximal flux $\left(J_{\max }^{*}\right)$ of different ACE inhibitors in in situ rat perfusion versus human oral bioavailability. 


\section{STRUCTURAL CONSIDERATIONS}

The "peptide" nature of cephradine, enalapril and TRH is demonstrated in Fig. 3 by a comparison of their chemical structures to the tripeptide, Phe-Ala-Pro. The $\beta$-lactams and ACE inhibitors which are absorbed by the peptide carrier-mediated transport system are dior tripeptide derivatives having at least one peptide bond and a free terminal carboxilic acid. Although a second peptide bond and an amino terminal or an $\alpha$-amino group exist in most $\beta$ lactams as in tripeptides, it is not a prerequisite for facilitated absorption, as can be seen from the non-passive absorption of the ACE inhibitors which are lacking a second peptide bond or a terminal amino group $[10,12]$. Recently, a $\beta$ lactam antibiotic without an $\alpha$-amino group, cefixime, has also been shown to be non-passively absorbed [7]. Furthermore, the ACE inhibitors enalapril and lisinopril have only the amino residue of the second amino acid group while SQ 29,852 is totally devoid of a second peptide bond (which is replaced with a phosphonic group ) yet still exhibits non-passive absorption $[11,12]$.

The nature of the side chains of the amino
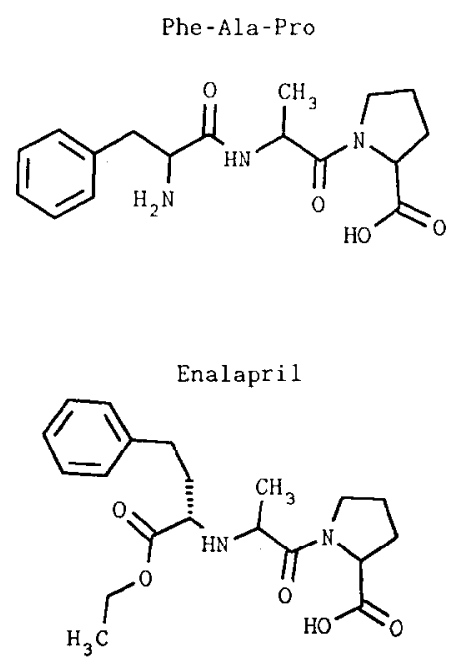

acids comprising the peptide drugs is also important for drug-carrier recognition and facilitated absorption. Numerous series of ACE inhibitors with rings of varying size replacing the proline side chain or different second or third amino acid side chains have been synthesized in order to obtain orally active ACE inhibitors [17-20]. A notable inconsistency between in vitro ACE inhibition and oral activity of the various derivatives prevails throughout the different series of ACE inhibitor analogues synthesized. The best intravenous or in vitro ACE inhibitors are not necessarily the most potent orally [17-20].

Although the inconsistency between in vitro ACE inhibition and oral activity among these derivatives hints towards facilitated absorption, no evidence for facilitated absorption has yet been published for most of the orally active ACE inhibitors. Considering their zwitterionic nature and the cumulative data on the non-passive absorption of peptide drugs, it may be hypothesized that those which are orally active are absorbed in a facilitated manner. However, oral activity by passive diffusion only may be the case for those zwitterions have large dominant hydrophobic residues such as in fosinopril [11].
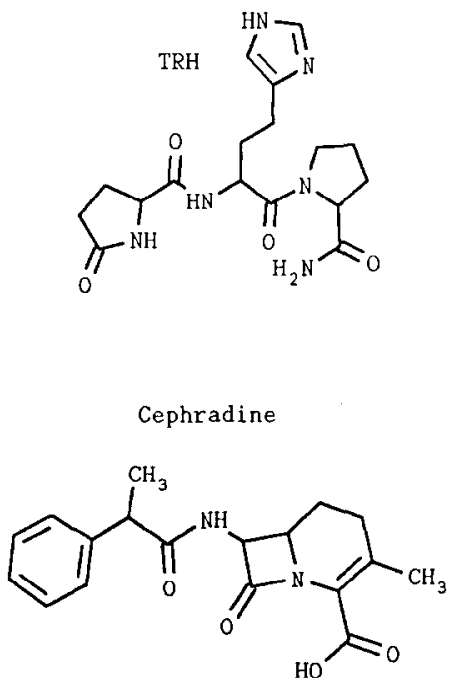

Fig. 3. Comparison of the chemical structures of the peptide drugs cephradine, enalapril and TRH to the tripeptide PheAla-Pro. 
Further characterization of the structural requirements of the peptide transporter will considerably aid in the development of small peptides with high oral efficacy.

\section{ACKNOWLEDGMENT}

This work was supported in parts by a grant from the National Institute of General Medical Sciences, GM 37188.

\section{REFERENCES}

1 D.H. Alpers, Digestion and absorption of carbohydrates and proteins, in: L.R. Johnson (Ed.), Physiology of the Gastro-Intestinal Tract, Raven Press, New York, NY, 1987, pp. 1469-1487.

2 A. Tsuji, E. Nakashima, I. Kagami and T. Yamana, Intestinal absorption mechanism of amino- $\beta$-lactam antibiotics. I: Comparative absorption and evidence for saturable transport of amino- $\beta$-lactam antibiotics by in situ rat small intestine, J. Pharm. Sci., 70 (1981) 768-773.

3 E. Nakashima, A. Tsuji, S. Kagatani and T. Yamana, Intestinal absorption mechanism of amino- $\beta$-lactam antibiotics. III. Kinetics of carrier-mediated transport across the rat small intestine in situ. J. Pharm. Dyn., 7 (1984) 452-464.

4 E. Nakashima, A. Tsuji, H. Mizuo and T. Yamana, Kinctics and mechanism of in vitro uptake of amino$\beta$-lactam antibiotics by rat small intestine and relation to the intact-peptide transport system, Biochem. Pharmacol., 33 (1984) 3345-3352.

5 M. Hu, P.J.Sinko, A.L.J. DeMeere, D.A. Johnson and G.L. Amidon, Membrane permeability for some amino acids and $\beta$-lactam antibiotics: application of the boundary layer approach. J. Theor. Biol., 131 (1988) 107-114.

6 P.J. Sinko and G.L. Amidon, Characterization of oral absorption of $\beta$-lactam antibiotics. I. Cephalosporins. Determination of intrinsic membrane absorption parameters in the rat intestine in situ, Pharm. Res., 5 (1988) 645-650.

7 A. Tsuji, T. Terasaki, I. Tamai and H. Hirroka, $\mathrm{H}^{+}$ gradient dependent and carrier-mediated transport of cefixime, a new cephalosporin antibiotic, across brushborder membrane vesicles from rat small intestine, J. Pharmacol. Exp. Ther., 241 (1986) 594-601.

8 M.J. Humphrey and P.S. Ringrose, Peptides and related drugs: A review of their absorption, metabolism, and excretion. Drug Met. Rev., 11 (1986) 283-310.

9 F.R. Atherton, M.J. Hall, C.H. Hassall, S.W. Holmes, R.W. Lambert, W.J. Lloyd and P.S. Ringrose, Phosphonopeptide antibacterial agents related to alafos- falin: Design, synthesis, and structure-activity relationship, Antimicrob. Agents Chem., 18 (1980) 897 905.

10 M. Hu and G.L. Amidon, Intestinal absorption of captopril in rats, J. Pharm. Sci., 77 (1988) 1007-1011.

11 D.I. Friedman and G.L. Amidon, Passive and carriermediated intestinal absorption components of two ACE inhibitor prodrugs in rats: enalapril and fosinopril, Pharm. Res., 6 (1990) 1043-1047.

12 D.I. Friedman and G.L. Amidon, Intestinal absorption mechanism of dipeptide ACE inhibitors of the lysyl-proline type: Lisinopril and SQ 29,852, J. Pharm. Sci., 78 (1989) 995-998.

13 D.A. Johnson and G.L. Amidon, Determination of intrinsic membrane transport parameters from perfused intestine experiments: A boundary layer approach to estimating the aqueous and unbiased membrane permeabilities, J. Theor. Biol., 131 (1988) 93-106.

14 K. Inui, T. Okano, H. Maegawa, M. Kato, M. 'Iakano and R. Hori, $\mathrm{H}^{+}$coupled transport of P.O. cephalosporins via dipeptide carriers in rabbit intestinal brushborder membranes: Difference of transport characteristic between cefixime and cephradine, J. Pharmacol. Exp. Ther., 247 (1988) 235241.

15 Martindale The Extra Pharmacopoeia, 29th edn., J.E.F. Reynolds (Ed.), The Pharmaceutical Press, London, 1989.

16 G.L. Amidon, P.J. Sinko and D. Fleisher, Estimating human oral fraction dose absorption: A correlation using rat intestinal membrane permeability for passive and carrier-mediated compounds, Pharm. Res., 5 (1988) 651-654.

17 J.L. Stanton, J.W.H. Watthey, M.N. Desai, B.M. Finn, J.E. Babiarz and H.C. Tomaselli, ACE inhibitors: Structure-activity profile of 1-benzazepin-2-one derivatives, J. Med. Chem., 28 (1985) 1603-1606.

18 D.S. Karanewsky, M.C. Badia, D.W. Cushman, J.M. DeForrest, T. Dejneka, M.J. Loots, M.G. Perri, E.W. Petrillo and J.R. Powell, (Phosphinyloxy) acyl amino acid inhibitors of ACE. I. Discovery of a novel orally active inhibitor of ACE, J. Med. Chem., 31 (1988) 204212.

19 J. Krapcho, C. Turk, D.W. Cushman, J.R. Powell, J.M DeForrest, E.R. Spitzmiller, D.S. Karanewsky, M. Duggan, G. Rovnyak, J. Schwartz, S. Natarajan, J.D. Godfrey, D.E. Ryono, R. Neubeck, K.S. Atwal and W. Petrillo, ACE inhibitors. Mercapto, carboxyl dipeptide, and phosphinic acid inhibitors incorporating 4substituted prolines, J. Med. Chem., 31 (1988) 1148 1160.

20 S. Klutchko, C.J. Blankley, R.W. Fleming, A.E. Werner, I. Nordin, A. Holmes, M.L. Hoefle, D.M. Cohen, A.D. Essenburg and H.R. Kaplan, Synthesis of novel ACE inhibitor quinapril and related compounds. A divergence of structure-activity relationship for nonsulfhydryl and sulfhydryl types, J. Med. Chem., 29 (1986) 1953-1961.

21 D.I. Friedman and G.L. Amidon, unpublished results, 1989. 